\title{
Detección y expresión de superantígenos y de resistencia antimicrobiana en aislamientos obtenidos de mujeres portadoras de Staphylococcus aureus que cuidan y alimentan niños
}

\author{
Yina Marcela Guaca-González¹, Gladys Fernanda Flórez-Restrepo², José Ignacio Moncayo-Ortiz', \\ Jorge Santacruz-Ibarra ${ }^{1}$, Adalucy Álvarez-Aldana ${ }^{1}$ \\ 1 Facultad de Ciencias de la Salud, Universidad Tecnológica de Pereira, Pereira, Colombia \\ 2 Centro de Biología Molecular y Biotecnología, Universidad Tecnológica de Pereira, Pereira, Colombia
}

Introducción. Staphylococcus aureus coloniza mucosas y piel, y causa graves infecciones en el hombre y los animales. Es importante establecer el estatus de portadoras de cepas enterotoxigénicas de este microorganismo en manipuladoras de alimentos, con el fin de prevenir intoxicaciones alimentarias.

Objetivo. Establecer las correlaciones entre los genes de enterotoxinas clásicas, el gen tsst-1, la producción de toxinas en cultivo y la resistencia antimicrobiana en aislamientos de $S$. aureus provenientes de manipuladoras de alimentos que cuidan niños en sus comunidades.

Materiales y métodos. Se cultivaron muestras de las fosas nasales y las yemas de los dedos de las manos, y se identificó $S$. aureus empleando las pruebas de rutina y métodos automatizados. La extracción de ADN se hizo mediante el método de bromuro de cetil-trimetil-amonio (Cetyl-TrimethylAmmonium Bromide, CTAB) modificado. Para la detección de superantígenos se emplearon pruebas de reacción en cadena de la polimerasa (PCR) simple y múltiple, y para la de toxinas, estuches comerciales. Resultados. Se encontró que el $22,0 \%$ de los aislamientos correspondía a portadoras de $S$. aureus: $17,0 \%$ en los aislamientos de fosas nasales; $5,0 \%$ en los de las manos y 6,7 \% simultáneamente en los dos sitios. La prevalencia de superantígenos fue de 73,7\%. El genotipo más frecuente fue el seatsst-1, con 10,0 \%. La resistencia a un solo antibiótico fue de 74,7 \% y, a cuatro antibióticos, de 3,2 \%; de los aislamientos, el 93,7 \% correspondía a cepas productoras de betalactamasas. La detección de genes clásicos y de tsst- 1 mediante PCR fue de 48,4 \% y la de toxinas en el sobrenadante, de 42,1\%, con una correlación de 95,7\%. Las mayores correlaciones se establecieron entre las toxinas TSST-1 (22/22) y SEA (17/18). La correlación del gen tsst- 1 con la proteína y la resistencia fue de $100 \%$. Todos los aislamientos con el genotipo sea-tsst- $1 \mathrm{t}$ fueron resistentes y productores de las toxinas.

Conclusión. La tasa de aislamientos de $S$. aureus toxigénicos y resistentes obtenidos de mujeres que cuidan y preparan alimentos para niños fue de más de $70 \%$, lo que demostró su gran virulencia y la consecuente necesidad de aplicar estrictamente las normas higiénicas y sanitarias vigentes para evitar el riesgo de intoxicación alimentaria.

Palabras clave: Staphylococcus aureus; enterotoxinas; farmacorresistencia microbiana; superantígenos; genotipo; variación genética.

doi: https://doi.org/10.7705/biomedica.v38i0.3653

Detection and expression of superantigens and resistance in isolates from women carriers of Staphylococcus aureus who take care of and feed children

Introduction: Staphylococcus aureus colonizes mucous membranes and skin causing severe infections in humans and animals. It is important to determine carrier status of enterotoxigenic strains of this microorganism in food handlers to prevent food poisoning.

Objective: To establish the correlations among classic enterotoxigenic genes, tsst-1 gene, the production of toxins in cultures and antimicrobial resistance in $S$. aureus isolates from women who handle the food, feed and take care of children in their communities.

Materials and methods: Nasal swab and finger samples were cultured and S. aureus was identified using routine methods and automated systems. DNA extraction was done by the CTAB modified method, and superantigen detection by simple and multiplex PCR, while toxins were detected using commercial kits.

\section{Contribución de los autores:}

Yina Marcela Guaca-González: estandarización de los métodos moleculares e identificación de la bacteria

Gladys Fernanda Flórez-Restrepo: procesamiento de muestras, aplicación de técnicas moleculares y base de datos

José Ignacio Moncayo-Ortiz: elaboración del proyecto de investigación y escritura del manuscrito

Jorge Santacruz-Ibarra: toma y procesamiento de muestras e identificación de la bacteria

Adalucy Álvarez-Aldana: toma de muestras y estandarización de métodos 
Results: We found that $22.0 \%$ of subjects were $S$. aureus carriers: $17.0 \%$ corresponded to nose samples, $5.0 \%$ to hands and $6.7 \%$ to both nose and hands. The prevalence of superantigens was $73.7 \%$. The most frequent genotype was sea-tsst-1 with $10 \%$. Resistance to one antibiotic was $74.7 \%$, and to four antibiotics, $3.2 \% ; 93.7 \%$ of the isolates were betalactamase-positive. Classical genes and tsst-1 gene were detected by PCR in $48.4 \%$ of samples and toxins in supernatant were detected in $42.1 \%$ of them with $95.7 \%$ of correlation. The highest correlations were established for TSST-1 and SEA with $100 \%$ and $94.4 \%$, respectively. The correlation of tsst-1 gene with toxin production and resistance was $100 \%$. All isolates with genotype sea-tsst-1 were toxin-positive and resistant.

Conclusion: The rate of toxigenic and resistant $S$. aureus isolates from women in charge of feeding and taking care of children was higher than $70 \%$, which demonstrates its high virulence. This requires the strict application of hygienic and sanitary regulations in order to avoid the risk of food poisoning.

Key words: Staphylococcus aureus; enterotoxins; drug resistance, microbial; superantigens; genotype; genetic variation.

doi: https://doi.org/10.7705/biomedica.v38i0.3653

Staphylococcus aureus es un patógeno extraordinariamente versátil que puede sobrevivir en condiciones ambientales hostiles, colonizar las mucosas y la piel, y causar graves infecciones purulentas mediadas por toxinas en el hombre y los animales (1). Entre las infecciones que causa, están las de tejidos blandos y de la piel, las asociadas a la atención en salud, las resultantes de la intoxicación alimentaria y algunas especialmente agresivas, como el síndrome de choque tóxico, la endocarditis, la meningitis, la osteomielitis y la neumonía $(2,3)$.

El estado de portador de $S$. aureus establecido a partir de muestras de mucosa nasal es un reconocido factor de riesgo para desarrollar infecciones por estafilococos y una fuente reconocida de diseminación de bacterias virulentas y resistentes a los antibióticos en los hospitales y la comunidad. El estado de portador de $S$. aureus en manipuladores de alimentos tiene un papel muy importante en la intoxicación alimentaria, principalmente cuando se trata de cepas enterotoxigénicas $(4,5)$.

Se reconocen tres patrones de portadores de $S$. aureus en los seres humanos: el persistente, el intermitente, y quien no es portador. Entre el 10 y el $35 \%$ de los individuos sanos son portadores persistentes, es decir, casi siempre portan una cepa de $S$. aureus; entre el 20 y el $75 \%$ de los individuos son portadores en forma intermitente, y, por último, entre 5 y $50 \%$ casi nunca son portadores $(6,7)$.

La virulencia de $S$. aureus es muy compleja, ya que involucra numerosos factores y diversos sistemas de

\footnotetext{
Correspondencia:

José Ignacio Moncayo-Ortiz, Facultad de Ciencias de la Salud, Universidad Tecnológica de Pereira, Carrera 27 No 10-02, Pereira, Colombia

Teléfono: (300) 6120392

jimo@utp.edu.co
}

Recibido: 18/11/16; aceptado: 26/05/17 regulación (8). Se han descrito muchos factores de virulencia, como la producción de enzimas, de toxinas y de superantígenos (SAg), así como la resistencia a los antibióticos, lo cual potencia su habilidad para colonizar y causar enfermedades $(2,3,8,9)$.

En los últimos años, se ha estudiado ampliamente la presencia de superantígenos en los aislamientos de $S$. aureus. Muchas cepas producen una o más exoproteínas que incluyen numerosas enterotoxinas, como la enterotoxina estafilocócica (Staphylococcal Enterotoxin, SE), la toxina del síndrome del choque tóxico (Toxic Shock Syndrome Toxin, TSST,), las toxinas exfoliativas (Exfoliative Toxins, ET) y las leucocidinas (Panton-Valentine Leukocidin, PVL) (9).

Los superantígenos poseen la capacidad de activar entre el 5 y el $20 \%$ de los linfocitos $\mathrm{T}$, lo que conlleva una producción masiva de citocinas proinflamatorias y quimiocinas que pueden causar desde fiebre e hipotensión hasta un choque letal $(2,8,10,11)$.

Se han identificado cinco clases de enterotoxinas clásicas codificadas por los genes sea, seb, sec, sed y see, y una toxina del síndrome del choque tóxico codificada por el gen tsst-1. Además, se han descrito muchos nuevos tipos, denominados enterotoxinas no clásicas o enterotoxinas nuevas (11-15). Otro grupo de exoproteínas son las toxinas exfoliativas, codificadas por los genes eta, etb y etd, las cuales son responsables del síndrome de piel escaldada, el cual afecta especialmente a niños y jóvenes $(16,17)$.

La prevalencia de los genes de superantígenos en los aislamientos de $S$. aureus de diferentes orígenes y áreas geográficas, varía ampliamente. Muchos estudios clínicos han intentado establecer una correlación entre la detección de los super- 
antígenos de $S$. aureus aislados de pacientes con infecciones estafilocócicas, pero esta no se ha establecida de una manera concluyente (10,17-19).

Los manipuladores de alimentos que son portadores de cepas de $S$. aureus productoras de enterotoxinas y otras exoproteínas aisladas de muestras de fosas nasales y manos, constituyen la más importante fuente de intoxicación alimentaria estafilocócica mediante el contacto manual o mediante las secreciones respiratorias, las cuales contaminan los alimentos durante su manipulación y preparación $(6,7,20)$.

El objetivo del estudio fue establecer la correlación entre la detección de los genes que codifican las enterotoxinas clásicas (sea, seb, sec, sed y see), el gen de la toxina del síndrome del choque tóxico (tsst-1), la expresión de las toxinas SEA, SEB, SEC, SED, SEE y TSST-1 en los sobrenadantes del cultivo, y la resistencia a los antibióticos en aislamientos de $S$. aureus obtenidos de las fosas nasales y las yemas de los dedos de manos de mujeres manipuladoras de alimentos encargadas del cuidado de niños en sus comunidades. Además, se detectaron las toxinas exfoliativas de los genes eta, etb y etd.

\section{Materiales y métodos}

Se hizo un estudio descriptivo con una fase analítica experimental de aislamientos de $S$. aureus provenientes de muestras de fosas nasales y manos de portadoras colombianas cuya principal función era el cuidado y la alimentación de niños de la comunidad donde residían. La población estuvo constituida por 406 mujeres.

Las muestras para el cultivo se obtuvieron con un escobillón estéril humedecido en solución salina fisiológica estéril de las fosas nasales y de las yemas de los dedos de las manos. Las muestras se tomaron, se procesaron y se cultivaron en agar manitol salado y rojo de fenol (Oxoid) en el Laboratorio de Microbiología de la Facultad de Ciencias de la Salud de la Universidad Tecnológica de Pereira.

La identificación de $S$. aureus se hizo mediante las técnicas de rutina (coloración de Gram, coagulasa y termonucleasa), y se confirmó usando el sistema automatizado Vitek $2^{\circledR}$ (Biomerieux) en colaboración con el laboratorio clínico del área de microbiología del Hospital Universitario San Jorge de Pereira. Con este sistema automatizado, también se determinó la sensibilidad a 13 antibióticos, en tanto que la producción de betalactamasas se estableció con sensidiscos de cefinasa.
Los aislamientos identificados como $S$. aureus se almacenaron en caldo de cultivo de cerebro y corazón (Oxoid) con glicerol al $20 \%$ y se conservaron a $-80^{\circ} \mathrm{C}$ para la posterior extracción de ADN y el análisis genotípico mediante PCR.

\section{Extracción de ADN}

Se hicieron cultivos de los aislamientos de $S$. aureus almacenados a $-80^{\circ} \mathrm{C}$ en agar de tripticasa de soya (Oxoid), y se incubaron durante 16 a 24 horas a $37^{\circ} \mathrm{C}$, para luego proceder a la extracción de ADN. La extracción del ADN genómico se hizo con el método de bromuro de cetil-trimetil-amonio (CTAB) (21) modificado para usar lisostafina (22-24). El ADN extraído se almacenó a $-20^{\circ} \mathrm{C}$ en alícuotas de $20 \mathrm{ng} / \mu \mathrm{l}$ para su posterior análisis molecular.

\section{Detección genotípica de los superantígenos en los aislamientos de Staphylococcus aureus}

La detección de los genes que codifican superantígenos se hizo mediante PCR múltiple (PCR-M) en dos series, $A$ y $B$, según lo descrito por Merhotra, et al., Ruzickova, et al., y Omoe, et al. (25-27). La técnica se estandarizó con las cepas de referencia de S. aureus ATCC: 700679 (Mu50), BAA-1707 (MW2), 13565 (196E), 13566 (S6) y 19095 en aislamientos clínicos previamente caracterizados en nuestro laboratorio, en los cuales se habían detectado uno o más genes de superantígenos.

En las pruebas de PCR, se utilizó como control positivo una mezcla de ADN de cepas de referencia que amplificaron todos los genes estudiados $y$, como control negativo, agua desionizada estéril. Como control interno de las reacciones, se utilizó la pareja de iniciadores femA1 y femA2.

La serie A se utilizó para detectar los genes de las enterotoxinas clásicas sea, seb, sec, sed y see; con la serie $\mathrm{B}$, se detectaron los genes de las toxinas exfoliativas de eta, etb, etd y la toxina del síndrome de choque tóxico TSST-1, utilizando para ambas series los iniciadores mencionados (25-27).

La reacción de amplificación de ambas series se efectuó en un volumen final de $25 \mu \mathrm{l}$ con solución tampón 1X $(\mathrm{KCl} 50 \mu \mathrm{M}$, tris- $\mathrm{HCl} 10 \mu \mathrm{M} ; \mathrm{pH} 8,0)$, $\mathrm{MgCl}_{2} 3 \mathrm{mM}$, dNTP $200 \mu \mathrm{M}$, y con 20 pmoles de los iniciadores de sea, seb, sec, see y 40 pmoles de sed para la serie A; y 20 pmoles de los iniciadores de eta etb y tsst-1, $1 \mathrm{U}$ de Taq polimerasa (Invitrogen) y $3 \mu \mathrm{l}$ de ADN con una concentración de $20 \mathrm{ng} / \mu \mathrm{l}$, para la serie $B$. 
Se utilizó un termociclador MasterCycler Gradient ${ }^{\circledR}$ (Eppendorf) con un programa de temperaturas consistente en una desnaturalización inicial a $96^{\circ} \mathrm{C}$ durante 3 minutos, seguida de 35 ciclos de desnaturalización a $94^{\circ} \mathrm{C}$ durante 1 minuto, anillamiento a $53^{\circ} \mathrm{C}$ durante 45 segundos, una extensión a $74^{\circ} \mathrm{C}$ durante1 minuto y un paso final de extensión durante 7 minutos a $72{ }^{\circ} \mathrm{C}$.

Se tomaron $10 \mu \mathrm{l}$ de los productos de cada serie y se corrieron por electroforesis con gel de agarosa al $2 \%$ en solución tampón TAE 1X (Tris-EDTA; $\mathrm{pH} 8,0)$ a 70 voltios durante una hora. Se utilizó un marcador de peso molecular marca Bioline (HyperLadder IVTM) y se tiñó con SYBR Safe. Los resultados se observaron en un fotodocumentador Gel Doc XR+ System ${ }^{\mathrm{TM}}$ de Bio-Rad, con un programa de Image Lab.

Detección de las proteínas de las enterotoxinas clásicas (SEA-SEE) y de la toxina del síndrome de choque tóxico (TSST-1) mediante ELISA y aglutinación

Los aislamientos preservados a $-80{ }^{\circ} \mathrm{C}$, positivos para uno o más genes de enterotoxinas clásicas, y el gen tsst-1, se recuperaron en caldo $\mathrm{BHI}$ y se incubaron durante 18 a 24 horas a $37^{\circ} \mathrm{C}$. Las enterotoxinas clásicas se detectaron en el sobrenadante del caldo de cultivo en fase estacionaria, utilizando el estuche Rida Screen Set $A, B, C, D, E^{\circledR}$, con un límite de detección para el sobrenadante del cultivo de $0,25 \mathrm{ng} / \mathrm{ml}$ (R-Biopharm); para la detección de la toxina del síndrome de choque tóxico, se empleó el estuche TST-RPLA, con sensibilidad de $2 \mathrm{ng} / \mathrm{ml}$ (Oxoid). En ambos casos se siguieron las instrucciones de los fabricantes.

\section{Análisis estadístico}

La información se recopiló en una base de datos de Excel; se elaboraron tablas de contingencia y se analizaron diferentes correlaciones entre la presencia o la ausencia de genes de superantígenos, la sensibilidad antimicrobiana y la producción de las toxinas de superantígenos en los sobrenadantes del cultivo.

Se aplicó la prueba exacta de Fisher y se consideraron estadísticamente significativos valores de $\mathrm{p} \leq 0,05$, con un intervalo de confianza del $95 \%$.

\section{Consideraciones éticas}

Las participantes firmaron el consentimiento informado. El estudio fue aprobado y supervisado por el Comité de Bioética de la Universidad Tecnológica de Pereira.

\section{Resultados}

\section{Prevalencia del estado de portador}

La prevalencia del estado de portador de $S$. aureus en las mujeres manipuladoras de alimentos fue del $22 \%$ (89/406): 17,0 \% (69/406) en muestras de fosas nasales y $5,0 \%(20 / 406)$ en las de manos; en $6,7 \%(6 / 89)$ de las portadoras hubo colonización tanto en las muestras de fosas nasales como en las de manos.

\section{Prevalencia de uno o más de los genes de superantígenos}

La prevalencia de uno o más genes de superantígenos fue de $73,7 \%$ (70/95); la mayor prevalencia fue de $34,7 \%$ (33/95) para un solo gen. La mayor asociación se dio entre dos de los genes de superantígenos, con $24,2 \%$ (23/95), seguida de la encontrada entre tres y cuatro genes, con 10,5\% (10/95) y 4,2\% (4/95), respectivamente. En 26,3\% (25/95) de los aislamientos, no se detectaron los genes de superantígenos.

\section{Prevalencia individual de los genes de superantígenos en los aislamientos de Staphylococcus aureus}

El gen con mayor prevalencia fue el etd (45/95; $47,4 \%)$, seguido del tsst-1 (22/95; 23,2\%), el sea $(18 / 95 ; 18,9 \%)$, el sed $(13 / 95 ; 13,7 \%)$, el sec $(11 / 95 ; 11,6 \%)$ y el seb (8/95; $8,4 \%)$. Los genes see y eta fueron los de menor prevalencia (4/95; $4,2 \%)$. El gen etb no se detectó en ninguno de los aislamientos.

\section{Frecuencia de la asociación entre los genes de superantígenos}

La asociación de los genes de superantígenos permitió establecer ocho genotipos para dos o más genes. El genotipo de mayor frecuencia fue el seatsst-1, con $10 \%(7 / 70)$, seguido del genotipo seaetd-tsst-1, con 8,6\% (6/70) (cuadro 1). En las seis personas con aislamientos simultáneos en fosas nasales y manos, los genotipos fueron diferentes en cada pareja de aislamientos.

\section{Resistencia a los antibióticos}

El 74,7\% (71/95) de los aislamientos de $S$. aureus fueron resistentes a un antibiótico; 9,5\% (9/95), a dos; $6,3 \%$ (6/95), a tres, y 3,2\% (3/95), a cuatro antibióticos. El 6,3\% (6/95) de los aislamientos de $S$. aureus fueron sensibles y el 93,7\% (89/95) fueron productores de betalactamasas. Los aislamientos resistentes a la tetraciclina (TCY) fueron 
los más frecuentes (11,6\%; 11/95), seguidos por los resistentes a la oxacilina/cefoxitina (OXA/FOXMRSA) $(6,3 \% ; 6 / 95)$ y a la eritromicina (ERI) $(4,2 \%$; $4 / 95)$. Los resitentes a la clindamicina (CLI) fueron los menos frecuentes $(3,2 \%, 3 / 95)$.

Correlación entre la detección de los genes de superantígenos y la resistencia a los antibióticos

En el cuadro 2, se presentan las diferentes asociaciones entre la detección de los genes de superantígenos y la resistencia a los antibióticos. Mediante la prueba exacta de Fisher aplicada a las diferentes asociaciones, se evidenció una diferencia estadísticamente significativa solo para la tetraciclina, con un valor de $p=0,0277$.

\section{Producción de enterotoxinas clásicas y de toxina del síndrome del choque tóxico en el sobrenadante de los cultivos de Staphylococcus aureus}

En las pruebas ELISA y de aglutinación para la detección de las enterotoxinas clásicas y de la toxina del síndrome del choque tóxico en el sobrenadante del cultivo, se encontró que el 46,3\% (44/95) fueron positivas para una o más toxinas y el 42,1\% (40/95) fueron productoras de una o más enterotoxinas clásicas. La enterotoxina SEA fue la que se detectó con mayor frecuencia $(17,9 \%$; $17 / 95)$, seguida por la SEC $(10,5 \% ; 10 / 95)$, la SEB

Cuadro 1. Prevalencia de los genotipos de superantígenos en los aislamientos de Staphylococcus aureus

\begin{tabular}{ll}
\hline Genotipos & $\mathbf{n}(\%)$ \\
\hline sea, tsst-1 & $7(10,0)$ \\
sea, etd, tsst-1 & $6(8,6)$ \\
sec, etd & $5(7,1)$ \\
seb, sed & $3(4,3)$ \\
seb, sed, etd & $2(2,9)$ \\
sed, etd & $2(2,9)$ \\
sed, tsst-1 & $2(2,9)$ \\
etd, tsst-1 & $2(2,9)$ \\
\hline
\end{tabular}

$(4,2 \%(4 / 95)$, la SED $(2,1 \% ; 2 / 95)$ y la SEE $(2,1 \%$; 2/95). La toxina TSST-1 se detectó en $23,2 \%$ (22/95) de los aislamientos de $S$. aureus.

Correlación entre la detección de los genes de las enterotoxinas clásicas y del gen tsst-1 y sus toxinas en los sobrenadantes del cultivo

El número de aislamientos positivos para los genes de enterotoxinas clásicas y para el gen tsst-1 detectados mediante PCR, fue de 48,4 \% (46/95); en $42,1 \%(44 / 95)$ de ellos, se detectó la producción de la proteína mediante las técnicas ELISA y de aglutinación.

La correlación entre la detección de los genes de enterotoxinas clásicas y del gen tsst-1 con las respectivas toxinas, fue de $95,7 \%(44 / 46)$. La toxina TSST-1 se detectó en $100 \%$ (22/22) de los casos, seguida por las proteínas SEA (17/18), SEC (10/11), SEB (4/8), SEE (2/4) y SED (2/13) (cuadro 3).

Correlación entre la detección de los genes de enterotoxinas, el gen tsst-1, las toxinas y la resistencia a los antibióticos

La correlación entre la detección de los genes, la producción de toxinas en los sobrenadantes del cultivo y la resistencia a los antibióticos en los aislamientos de $S$. aureus, se presenta en el cuadro 4.

El análisis de los resultados evidenció que el gen tsst-1 se correlacionó en el $100 \%$ de los aislamientos con la detección de la proteína TSST1 (22/22), y con la resistencia a los antibióticos betalactámicos (22/22), a la eritromicina (2/2), a la clindamicina (2/2) y a la tetraciclina (3/3). El gen sea se correlacionó en $94,4 \%$ (17/18) de los aislamientos con la producción de la toxina SEA $y$, en $100 \%$, con la resistencia a oxacilina más cefoxitina (2/2), a eritromicina (2/2), a clindamicina (2/2) y a tetraciclina (3/3); su correlación con la resistencia a los antibióticos betalactámicos fue de

Cuadro 2. Asociación entre los genes de los superantígenos, el resultado de la prueba para betalactamasas y la resistencia a cefoxitina/oxacilina, eritromicina, clindamicina y tetraciclina

\begin{tabular}{|c|c|c|c|c|c|c|c|c|c|c|}
\hline \multirow[t]{2}{*}{ SAg/sensibilidad } & \multicolumn{2}{|c|}{$\begin{array}{c}\text { Prueba para } \\
\text { betalactamasas }\end{array}$} & \multicolumn{2}{|c|}{ OXA/FOX } & \multicolumn{2}{|c|}{ ERI } & \multicolumn{2}{|c|}{ CLI } & \multicolumn{2}{|c|}{ TCY } \\
\hline & $\mathbf{P}$ & $\mathbf{N}$ & $\mathbf{S}$ & $\mathbf{R}$ & $\mathbf{s}$ & $\mathbf{R}$ & $\mathbf{S}$ & $\mathbf{R}$ & $\mathbf{S}$ & $\mathbf{R}$ \\
\hline $\mathrm{SAg}+$ & 67 & 22 & 67 & 3 & 66 & 4 & 67 & 3 & 59 & 11 \\
\hline $\mathrm{SAg}^{-}$ & 3 & 3 & 22 & 3 & 25 & 0 & 25 & 0 & 25 & 0 \\
\hline Total & 70 & 25 & 89 & 6 & 91 & 4 & 92 & 3 & 84 & 11 \\
\hline $\mathrm{p}$ & \multicolumn{2}{|c|}{0,1844} & \multicolumn{2}{|c|}{0,1844} & \multicolumn{2}{|c|}{0,880} & \multicolumn{2}{|c|}{0,3954} & \multicolumn{2}{|c|}{0,0277} \\
\hline
\end{tabular}

SAg: superantígenos; P: positiva; N: negativa; S: sensible; R: resistente; OXA/FOX: oxacilina-cefoxitina; ERI: eritromicina; CLI: clindamicina; TCY: tetraciclina 
$94,4 \%$ (17/18). En cuanto al genotipo sea-tsst-1, todos los aislamientos fueron productores de las toxinas y resistentes a eritromicina, clindamicina y tetraciclina.

\section{Discusión}

El estado de portador de $S$. aureus en la población estudiada, se detectó en $22 \%$ de los aislamientos: $17 \%$ en muestras de fosas nasales y $5 \%$ en las de manos, porcentajes similares a los publicados por diferentes autores en individuos sanos, en quienes se ha establecido un rango de portadores de 20 a $40 \%$ en muestras de fosas nasales y de 5 a $10 \%$ en las de manos (28-30). El estado de portador es un potencial factor de riesgo para la diseminación de la bacteria y puede causar intoxicación alimentaria por manipulación de alimentos, así como otro tipo de infecciones estafilocócicas.

En este estudio se encontró que, en 6,7 \% (6/89) de las mujeres, el estatus de portador se detectó simultáneamente en las muestras de fosas nasales y de manos. No se encontraron estudios similares para hacer análisis comparativos, y los genotipos de los superantígenos en estos seis aislamientos no mostraron un patrón que permitiera concluir

Cuadro 3. Porcentaje de correlación entre la detección de los genes y toxinas SEA, SEB, SEC, SED, SEE Y TSST-1 mediante las técnicas ELISA y de aglutinación

\begin{tabular}{lccc}
\hline Gen & $\begin{array}{c}\text { Número de } \\
\text { genes detectados }\end{array}$ & $\begin{array}{c}\text { Número de } \\
\text { toxinas detectadas }\end{array}$ & $\%$ \\
\hline sea & 18 & 17 & 94,4 \\
seb & 8 & 4 & 50,0 \\
sec & 11 & 10 & 90,9 \\
sed & 13 & 2 & 15,4 \\
see & 4 & 2 & 50,0 \\
tsst-1 & 22 & 22 & 100 \\
\hline
\end{tabular}

que la colonización simultánea correspondía a la misma cepa toxigénica, por lo cual es necesario hacer estudios complementarios para determinar si existe o no 'clonalidad' en las cepas de $S$. aureus.

Además de velar por el bienestar de los niños a su cargo, las mujeres analizadas en el estudio les preparan los alimentos, es decir, también son manipuladoras de alimentos. La detección mediante PCR de los genes de superantígenos en los aislamientos, evidenció una prevalencia global de $73,7 \%$, resultado que se ubica en el rango de 71,0 a $86,6 \%$ encontrado en manipuladores de alimentos en Kuwait $(31,32)$, y similar a la prevalencia de $74,1 \%$ hallada en aislamientos de $S$. aureus de personas afectadas por intoxicación alimentaria en Taiwán (33). En estudios realizados en Latinoamérica, la detección de superantígenos en portadores de $S$. aureus ha sido superior a $50 \%(34,35)$.

Aunque no se encontró reportado en otros estudios en aislamientos de $S$. aureus de muestras nasales o de manos de portadores, el gen etd fue el más frecuente $(47,4 \%)$ de todos los valorados en este estudio, lo cual constituye un hallazgo importante. Se ha planteado que la proteína codificada por el gen etd puede interrumpir la barrera cutánea epitelial y contribuir, de esta manera, a la propagación bacteriana (36). Este gen ha sido reportado también en aislamientos clínicos, con una frecuencia de $10,5 \%$ (37).

Los genes tsst-1 y sea siguieron en frecuencia, con $23,2 \%$ y $18,9 \%$, respectivamente. Estos resultados concuerdan con hallazgos previos en individuos sanos portadores de $S$. aureus productores de las toxinas. Mehrotra, et al., y otros autores obtuvieron datos similares para los genes tsst-1 $(24,3 \%)$ y sea $(19,6 \%)(25,37-39)$. La distribución de estos genes es universal, y se pueden detectar en aislamientos clínicos, de alimentos y en portadores $(25,39,40)$.

Cuadro 4. Correlación entre la detección de los genes de las toxinas clásicas y el gen tsst-1, las toxinas en los sobrenadantes del cultivo y la resistencia a los antibióticos en los aislamientos de Staphylococcus aureus

\begin{tabular}{lccccr}
\hline $\begin{array}{l}\text { Gen/ } \\
\text { antibiótico }\end{array}$ & $\begin{array}{c}\text { Positivo para } \\
\text { betalactamasas }\end{array}$ & OXA/FOX & ERI & CLI & TCY \\
\hline Correlación \% (toxina/gen) & & & & & \\
\hline Sea & $94,4(17 / 18)$ & $100 \quad(2 / 2)$ & $100(2 / 2)$ & $100(2 / 2)$ & $100(3 / 3)$ \\
Seb & $50,0 \quad(4 / 8)$ & $\mathrm{NR}$ & $\mathrm{NR}$ & $\mathrm{NR}$ & $0,0(0 / 2)$ \\
Sec & $91,0(10 / 11)$ & $100 \quad(2 / 2)$ & $100(1 / 1)$ & $\mathrm{NR}$ & $100(2 / 2)$ \\
Sed & $15,4(2 / 13)$ & $\mathrm{NR}$ & $\mathrm{NR}$ & $\mathrm{NR}$ & $50,0(2 / 4)$ \\
See & $50,0(2 / 4)$ & $0,0(0 / 1)$ & $\mathrm{NR}$ & $\mathrm{NR}$ & $50,0(1 / 2)$ \\
tsst-1 & $100(22 / 22)$ & $\mathrm{NR}$ & $100(2 / 2)$ & $100(2 / 2)$ & $100(3 / 3)$ \\
\hline
\end{tabular}

NR: no se detectó resistencia; OXA/FOX: oxacilina-cefoxitina; ERI: eritromicina;

CLI: clindamicina; TCY: tetraciclina 
El gen sea apareció principalmente asociado a tsst1 y etd, con una prevalencia de $10 \%$ para el genotipo sea-tsst-1 y de 8,6\% para el genotipo sea-etdtsst-1, lo cual demuestra que es dominante en estas asociaciones y se puede relacionar con cualquier tipo de genes de superantígenos en aislamientos de diferentes orígenes (41). La importancia de este gen se ha demostrado en diferentes estudios que lo reportan como uno de los factores importantes en la intoxicación alimentaria (39).

Las asociaciones establecidas entre tsst-1-etd y sea-etd-tsst-1 en este estudio, son variantes aún no descritas por los autores de los artículos revisados. La información sobre las asociaciones de enterotoxinas clásicas, de la toxina del síndrome de choque tóxico y de las toxinas exfoliativas, es escasa $(42,43)$; por ello, es necesario seguir investigando su verdadero impacto en la patogenia de $S$. aureus.

En el análisis de la sensibilidad a los antimicrobianos probados, se evidenció que $74,7 \%$ presentó resistencia a uno o más antibióticos, lo cual concuerda con los reportes de Teixeira, et al. (44). Staphylococcus aureus puede producir betalactamasas codificadas por genes cromosómicos o plasmídicos; $93,7 \%$ de los aislamientos analizados fueron positivos para betalactamasas, lo cual concuerda con el $96 \%$ reportado por Seo, et al. Por otra parte, la multirresistencia de $3,2 \%$ a cuatro antibióticos encontrada en el presente estudio, difiere mucho del porcentaje obtenido (56\%) por Seo, et al. (41). La resistencia antimicrobiana de los aislamientos sugiere que el estado de portador es una fuente potencial de diseminación de cepas resistentes a los antibióticos.

Los resultados para los 13 antimicrobianos estudiados indicaron que, después de la producción de betalactamasas, el mayor porcentaje de resistencia $(11,6 \%)$ se presentó frente a la tetraciclina, similar al reportado por Morales, et al., (16\%) (45).

Al determinar la correlación entre superantígenos y resistencia antimicrobiana, la única diferencia estadísticamente significativa fue para la sensibilidad a la tetraciclina. Si bien la tetraciclina no es el antimicrobiano de elección en el tratamiento, la asociación entre la sensibilidad frente a su efecto y la presencia de superantígenos se convierte en un hallazgo que se debe tener en cuenta, por lo cual deben hacerse más estudios para establecer la correlación entre la presencia de superantígenos y la sensibilidad a los antimicrobianos.
En este estudio se estableció que la correlación entre la detección de las toxinas en el sobrenadante del cultivo en los aislamientos que amplificaron para los genes de las enterotoxinas clásicas y el gen tsst-1, fue de 95,7\%. En este sentido, Bystron, et al., encontraron una correlación de $88,9 \%$ en aislamientos de $S$. aureus obtenidos de alimentos (46), en tanto que Zschock, et al., reportaron una de $98,8 \%$ en aislamientos de muestras de vacas con mastitis bovina (47). Esto sugiere que existe una fuerte correlación entre el fenotipo y el genotipo, independientemente de la procedencia de los aislamientos.

Por último, las correlaciones entre la detección de genes, la producción de las toxinas y la resistencia a los antibióticos, permitieron sugerir que la expresión de los genes in vitro es un buen marcador para determinar el potencial patogénico de aislamientos de $S$. aureus en estas cuidadoras de niños.

Este estudio demostró la gran virulencia de los aislamientos de $S$. aureus obtenidos de mujeres que cuidan y preparan alimentos para niños, ya que, al correlacionar la presencia de los genes de superantígenos y la resistencia antimicrobiana, se encontró una tasa de aislamientos toxigénicos y resistentes mayor de $70 \%$, lo que implica que eran potencialmente patógenos, y exigiría la aplicación estricta de las normas higiénicas y sanitarias vigentes para evitar el riesgo de intoxicación alimentaria.

\section{Agradecimientos}

A la Universidad Tecnológica de Pereira, por la financiación y el apoyo durante el desarrollo de la investigación; también, al Instituto Colombiano de Bienestar Familiar seccional Pereira y al Laboratorio Clínico del Hospital Universitario San Jorge.

\section{Financiación}

Este estudio se financió con recursos de una convocatoria interna de la Universidad Tecnológica de Pereira, Risaralda, Colombia.

\section{Conflicto de intereses}

Los autores no presentan conflictos de intereses.

\section{Referencias}

1. Chen CJ, Want SC, Chang HY, Huang YC. Longitudinal analysis of methicillin-resistant and methicillin-susceptible Staphylococcus aureus carriage in healthy adolescents. J Clin Microbiol. 2013;51:2508-14. https://doi.org/10.1128/ JCM.00572-13

2. Larkin EA, Carman RJ, Krakauer T, Stiles BG. Staphylococcus aureus: The toxic presence of a pathogen extraordinaire. Curr Med Chem. 2009;16:4003-19. https:// doi.org/10.2174/092986709789352321 
3. Bronner S, Monteil H, Prévost G. Regulation of virulence determinants in Staphylococcus aureus: Complexity and applications. FEMS Microbiol Rev. 2004;28:183-200. https:// doi.org/10.1016/j.femsre.2003.09.003

4. Kluytmans J, van Belkum A, Verbrugh H. Nasal carriage of Staphylococcus aureus: Epidemiology, underlying mechanisms, and associated risks. Clin Microbiol Rev. 1997;10:505-20.

5. Wertheim HF, Melles DC, Vos MC, van Leeuwen W, van Belkum A, Verbrugh HA, et al. The role of nasal carriage in Staphylococcus aureus infections. Lancet Infect Dis. 2005; 5:751-62. https://doi.org/10.1016/S1473-3099(05)70295-4

6. Kluytmans JA, Wertheim HF. Nasal carriage of Staphylococcus aureus and prevention of nosocomial infections. Infection. 2005;33:3-8. https://doi.org/10.1007/s15010-0054012-9

7. Argudin MA, Mendoza MC, Rodicio MR. Food poisoning and Staphylococcus aureus enterotoxins. Toxins (Basel). 2010;2:1751-73. https://doi.org/10.3390/toxins2071751

8. François P, Scherl A, Hochstrasser D, Schrenzel J. Proteomic approaches to study Staphylococcus aureus pathogenesis. J Proteomics. 2010;73:701-8. https://doi. org/10.1016/j.jprot.2009.10.007

9. Dinges MM, Orwin PM, Schlievert PM. Exotoxins of Staphylococcus aureus. Clin Microbiol Rev. 2000;13:16-34. https://doi.org/10.1128/CMR.13.1.16-34.2000

10. Varshney AK, Mediavilla JR, Robiou N, Guh A, Wang X, Gialanella $\mathbf{P}$, et al. Diverse enterotoxin gene profiles among clonal complexes of Staphylococcus aureus isolates from the Bronx, New York. Appl Environ Microbiol. 2009;75:683949. https://doi.org/10.1128/AEM.00272-09

11. Kuroda M, Ohta T, Uchiyama I, Baba T, Yuzawa $\mathbf{H}$, Kobayashi I, et al. Whole genome sequencing of methicillinresistant Staphylococcus aureus. Lancet. 2001;357:122540. https://doi.org/10.1016/S0140-6736(00)04403-2

12. McCormick JK, Yarwood JM, Schlievert PM. Toxic shock syndrome and bacterial superantigens: An update. Annu Rev Microbiol. 2001;55:77-104. https://doi.org/10.1146/ annurev.micro.55.1.77

13. Jarraud S, Peyrat MA, Lim A, Tristan A, Bes M, Mougel C, et al. egc, a highly prevalent operon of enterotoxin gene, forms a putative nursery of superantigens in Staphylococcus aureus. J Immunol. 2001;166:669-77. https://doi.org/10. 4049/jimmunol.166.1.669

14. Chiang YC, Liao WW, Fan CM, Pai WY, Chiou CS, Tsen HY. PCR detection of staphylococcal enterotoxins (SEs) N, $\mathrm{O}, \mathrm{P}, \mathrm{Q}, \mathrm{R}, \mathrm{U}$, and survey of SE types in Staphylococcus aureus isolates from food-poisoning cases in Taiwan. Int $\mathrm{J}$ Food Microbiol. 2008;121:66-73. https://doi.org/10.1016/j. ijfoodmicro.2007.10.005

15. Wilson G, Seo KS, Cartwright RA, Connelley $T$, Chuang-Smith ON, Merriman $\mathrm{J}$, et al. A novel core genome-encoded superantigen contributes to lethality of community-associated MRSA necrotizing pneumonia. PLoS Pathog. 2011;7:e1002271. https://doi.org/10.1371/journal. ppat. 1002271

16. Ladhani S, Joannou CL, Lochrie DP, Evans RW, Poston SM. Clinical, microbial, and biochemical aspects of the exfoliative toxins causing staphylococcal scalded-skin syndrome. Clin Microbiol Rev. 1999;12:224-42.
17. Plano LR. Staphylococcus aureus exfoliative toxins: How they cause disease. J Invest Dermatol. 2004;122:1070-7. https://doi.org/10.1111/j.1523-1747.2004.22144.x

18. Ferry T, Thomas D, Perpoint T, Lina G, Monneret G, Mohammedi I, et al. Analysis of superantigenic toxin $\mathrm{V} \beta$ T-cell signatures produced during cases of staphylococcal toxic shock syndrome and septic shock. Clin Microbiol Infect. 2008;14:546-54. https://doi.org/10.1111/j.1469-0691. 2008.01975.x

19. Fleischer B, Schrezenmeier H. T cell stimulation by staphylococcal enterotoxins. Clonally variable response and requirement for major histocompatibility complex class II molecules on accessory or target cells. J Exp Med. 1988; 167:1697-707. https://doi.org/10.1084/jem.167.5.1697

20. Jordan GB, Marucci RS, Guida AM, Pires PS, Manfredi EA. Portación y caracterización de Staphylococcus aureus en manipuladores de alimentos. Rev Argent Microbiol. 2012;44:101-4

21. Ausubel FM, Brent R, Kingston RE, Moore DD, Seidman JG, Smith JA, et al. Protocols in Molecular Biology. New York: Wiley Interscience; 1989

22. Johnson WM, Tyler SD, Ewan EP, Pollard DR, Rozee KR. Detection of genes for enterotoxins, exfoliative toxins, and toxic shock syndrome toxin 1 in Staphylococcus aureus by the polymerase chain reaction. J Clin Microbiol. 1991; 29:426-30

23. Corredor LF, Moncayo JI, Santacruz JJ, Álvarez A. Detección de genes de toxinas pirogénicas y toxinas exfoliativas en aislamientos clínicos de Staphylococcus aureus en Colombia. Investigaciones Andina. 2012;14:577-87.

24. Corredor LF, Luligo JS, Moncayo JI, Santacruz JJ, Álvarez A. Relationship between super antigenicity, antimicrobial resistance and origin of Staphylococcus aureus isolated. Colombia Médica.2016;47:90-5.

25. Merhotra M, Wang G, Johnson WM. Multiplex PCR for detection of genes for Staphylococcus aureus enterotoxins, exfoliative toxins, toxic shock syndrome toxin 1, and methicillin resistance. J Clin Microbiol. 2000;38:1032-35.

26. Ruzickova V, Voller J, Pantucek R, Petras P, Doskar J. Multiplex PCR for detection of three exfoliative toxin serotype genes in Staphylococcus aureus. Folia Microbiol (Praha). 2005;50:499-502.

27. Omoe K, Hu DL, Takahashi-Omoe H, Nakane A, Shinagawa K. Comprehensive analysis of classical and newly described staphylococcal superantigenic toxin genes in Staphylococcus aureus isolates. FEMS Microbiol Lett. 2005;246:191-8. https://doi.org/10.1016/j.femsle.2005.04.007

28. Lu PL, Chin LC, Peng CF, Chiang YH, Chen TP, Ma L, et al. Risk factors and molecular analysis of community methicillin-resistant Staphylococcus aureus carriage. J Clin Microbiol. 2005;43:132-9. https://doi.org/10.1128/JCM.43.1. 132-139.2005

29. Kuehnert MJ, Kruszon-Moran D, Hill HA, Mcquillan G, Mcallister SK, Fosheim G, et al. Prevalence of Staphylococcus aureus nasal colonization in the United States, 2001-2002. J Infect Dis. 2006;193:172-9. https://doi. org/10.1086/499632 
30. Wattinger L, Stephan R, Layer F, Johler S. Comparison of Staphylococcus aureus isolates associated with food intoxication with isolates from human nasal carriers and human infections. Eur J Clin Microbiol Infect Dis. 2012; 31:455-64. https://doi.org/10.1007/s10096-011-1330-y

31. Udo EE, Al-Mufti S, Albert MJ. The prevalence of antimicrobial resistance and carriage of virulence genes in Staphylococcus aureus isolated from food handlers in Kuwait City restaurants. BMC Res Notes. 2009;2:108. https://doi.org/10.1186/1756-0500-2-108

32. Al-Bustan MA, Udo EE, Chugh TD.Nasal carriage of enterotoxin producing Staphylococcus aureus among restaurant workers in Kuwait City. Epidemiol Infect. 1996;116: 319-22.

33. Chiang YC, Lin CW, Yang CY, Tsen HY. PCR primers for the detection of staphylococcal enterotoxin $\mathrm{K}, \mathrm{L}$, and $M$ and survey of staphylococcal enterotoxin types in Staphylococcus aureus isolates from food poisoning cases in Taiwan. J Food Prot. 2006;69:1072-9. https://doi. org/10.4315/0362-028X-69.5.1072

34. Figueroa G, Navarrete P, Caro M, Troncoso M, Faúndez G. Portación de Staphylococcus aureus enterotoxigénicos en manipuladores de alimentos. Rev Med Chile. 2002;130:85964. https://doi.org/10.4067/S0034-98872002000800003

35. Mamprim FA. Enterotoxinas de Staphylococcus coagulase positiva e negativa isoladas das fossas nasais e mãos de manipuladores de alimentos (dissertação). São Paulo, SP: Universidade Estadual Paulista; 2006.

36. Ladhani S. Understanding the mechanism of action of the exfoliative toxins of Staphylococcus aureus. Fems Immunol Med Microbiol. 2003;39:181-9. https://doi.org/10.1016/ S0928-8244(03)00225-6

37. Yamasaki O, Tristan A, Yamaguchi T, Sugai M, Lina G, Bes $M$, et al. Distribution of the exfoliative toxin $D$ gene in clinical Staphylococcus aureus isolates in France. Clin Microbiol Infect. 2006;12:585-8. https://doi.org/10.1111/j. 1469-0691.2006.01410.x

38. Chance TD. Toxic shock syndrome: Role of the environment, the host and the microorganism. Br J Biomed Sci. 1996;53:284-9.

39. Aydin A, Sudagidan M, Muratoglu K. Prevalence of staphylococcal enterotoxins, toxin genes and genetic-relatedness of foodborne Staphylococcus aureus strains isolated in the Marmara Region of Turkey. Int J Food Microbiol. 2011;148: 99-106. https://doi.org/10.1016/j.jfoodmicro.2011.05.007

40. Sospedra I, Manes J, Soriano JM. Report of toxic shock syndrome toxin 1 (TSST-1) from Staphylococcus aureus isolated in food handlers and surfaces from food service establishments. Ecotoxicol Environ Saf. 2012;80:288-90. https://doi.org/10.1016/j.ecoenv.2012.03.011

41. Seo YH, Jang JH, Moon KD. Occurrence and characterization of enterotoxigenic Staphylococcus aureus isolated from minimally processed vegetables and sprouts in Korea. Food Sci Biotechnol. 2010;19:313-9. https://doi.org/10. 1007/s10068-010-0045-7

42. Booth MC, Pence LM, Mahasreshti P, Callegan MC, Gilmore MS. Clonal associations among Staphylococcus aureus isolates from various sites of infection. Infect Immun. 2001;69:345-52. https://doi.org/10.1128/IAI.69.1. $345-352.2001$

43. Jarraud S, Mougel C, Thioulouse J, Lina G, Meugnier $\mathbf{H}$, Forey F, et al. Relationships between Staphylococcus aureus genetic background, virulence factors, agr groups (alleles), and human disease. Infect Immun. 2002;70:63141. https://doi.org/10.1128/IAI.70.2.631-641.2002

44. Teixeira LA, Resende CA, Ormonde LR, Rosenbaum R, Figueiredo AM, De Lencastre H, et al. Geographic spread of epidemic multiresistant Staphylococcus aureus clone in Brazil. J Clin Microbiol.1995;33:2400-4.

45. Morales MG, Ruiz-de Chávez CG. Diferencias en la resistencia a los antimicrobianos de cepas de Staphylococcus aureus obtenidas de diversas fuentes de aislamiento. Revista del Centro de Investigación. Universidad La Salle, México. 2006;7:45-64.

46. Bystron J, Bania J, Zarczynska A, Korzekwa K, Molenda J, Kosek K. Detection of enterotoxigenic Staphylococcus aureus strains using a commercial Elisa and multiplex-PCR. Bull Vet Inst Pulawy. 2006;50:329-33.

47. Zschöck M, Botzler D, Blöcher S, Sommerhäuser J, Hamann HP. Detection of genes for enterotoxins (ent) and toxic shock syndrome toxin-1 (tst) in mammary isolates of Staphylococcus aureus by polymerase-chain-reaction. Int Dairy J. 2000;10:569-74. https://doi.org/10.1016/S0958-6946 (00)00084-4 